\title{
O BRASIL E SUA HERANÇA ORIENTAL NA OBRA DE GILBERTO FREYRE
}

\section{THE BRAZIL AND ITS EASTERN HERITAGE IN THE WORK OF GILBERTO FREYRE}

\begin{abstract}
Amurabi Oliveira*
SILVA, Valéria Torres da Costa e. Orientalismos brasileiros: Gilberto Freyre e a peleja entre Vênus e a Moura Encantada. Recife: Carpe Diem Edições e Produções, 2011. 71 p.

Apesar de sua posição icônica no pensamento social brasileiro, a obra de Gilberto Freyre certamente é uma das mais controversas, alimentando calorosos debates ao menos desde os anos 30 do século XX, em especial no que tange a sua interpretação sui generis em torno das relações raciais no Brasil. Todavia, há um aspecto na obra de Freyre ainda pouco explorado, que diz respeito a sua análise em torno da influência oriental na formação cultural brasileira, o que é explorado neste breve, porém substancial, trabalho de Valéria Torres da Costa e Silva. Tal questão já havia chamado a atenção de outro pesquisador, Edson Nery da Fonseca, que em 2003 publicou uma coletânea de textos de Freyre intitulada China Tropical, na qual compilou fragmentos de obras diversas do sociólogo pernambucano que tocavam na questão oriental, porém não se aventurou a uma análise mais profunda acerca de tais aspectos, ainda que indique na "nota do organizador" que: "Um dos inúmeros pioneirismos de Gilberto Freyre foi a indicação de valores orientais absorvidos pelos portugueses e incorporados à cultura brasileira: uma cultura simbiótica, pra utilizar palavra de origem biológica por ele aplicada às ciências do homem".'

A autora do livro aqui resenhado inicia o texto com o capítulo intitulado "Entre o Prelúdio e a Primavera", no qual data fatos e relata acontecimentos de ordem global, indicando a forma como chegaram até ela.
\end{abstract}

*Professor na Universidade Federal de Alagoas (UFAL). E-mail: amurabi_cs@hotmail.com 
Inicia a narrativa pelo 11 de setembro de 2001, quando estava em Berkeley nos Estados Unidos, e ocorre o fatídico atentado às chamadas Torres Gêmeas, em Nova Iorque. A partir daí uma série de outros acontecimentos se sucedem, por meio dos quais é forjada uma nova concepção de oriente, associada principalmente ao universo árabe nesse momento.

Os fatos que ela sinteticamente relata abrangem uma década, culminando com o que se convencionou denominar de "Primavera Árabe", já no princípio da segunda década do século XXI, criam uma leitura muito particular sobre a democracia e a forma como ela deveria ser implementada no mundo árabe, o que passa a ser questionado por Silva, ao indicar que um projeto de democracia elaborado às custas da repressão dos valores culturais das sociedades em questão estaria fadado ao fracasso. A partir desse ponto ela introduz a reflexão de Freyre, apontando para a questão do Oriente na obra desse pensador. Conforme a Silva:

Em Casa-grande \& senzala $(C G \& S)$ e mais radicalmente em Sobrados e mucambos (SM), esse pensador desenvolve uma reflexão muito provocadora sobre as relações entre o Oriente e o Ocidente enquanto matrizes culturais. Num momento em que a Europa era o grande espelho no qual o Brasil tentava se mirar, Gilberto Freyre fez uma escolha deliberada por alinhar esse mesmo Brasil ao Oriente, invertendo os sinais - positivo e negativo - tradicionalmente associados a Ocidente e Oriente. A associação do Brasil ao Oriente, como paradigma cultural, permitiu a Gilberto Freyre produzir uma contundente crítica ao processo de modernização que o pais vinha sofrendo desde o século XIX. NA minha avaliação esse é um gesto epistemológico radical, surpreendentemente negligenciado pela fortuna crítica freyreana. E se foi precursor na década de 1930, continua sendo provocador no século XXI (p. 18-19).

A autora se esforça em nos demonstrar que a interpretação de Freyre, ao se desenvolver a partir da ideia de interpenetração das culturas, dissolve completamente as fronteiras entre o Oriente e o Ocidente, tomando o Brasil como um caso particular. É importante notar que a compreensão aqui assumida de Oriente é bastante ampla, envolvendo tanto a Ásia quanto a África muçulmana e os Judeus, o que se encontra em consonância com a leitura assumida por Freyre desde Casa-Grande \& Senzala, quando o autor já apontara como fundamental o contato com os $\mathrm{Mouros}^{2}$ para a formação do caráter plástico do português.

Voltando ao cenário atual, na tensa relação que se estabeleceu entre o Ocidente e Oriente, Silva afirma que são necessários nesse momento os dois principais pressupostos metodológicos advogados por Freyre já nos anos de 
1920 para as ciências sociais e da história: a compreensão e a empatia, para que por meio desses consigamos vislumbrar as possibilidades reais de se pensar a democracia no mundo árabe, caso essas nações façam a escolha por esse modelo político. Tais pressupostos que permitiram a Freyre perceber a herança híbrida existente no Brasil, na qual o Oriente não seria adereço, mas sim essência em termos culturais.

Por fim nesse primeiro capítulo, a autora anuncia que se converteu em uma admiradora de Gilberto Freyre, de modo a deixar suficientemente claro para os leitores a sua posição com relação ao legado intelectual analisado, convidando-os a adentrar no pensamento dele de forma desarmada, ainda que não negue as contradições existentes neste.

Em "Sob o Signo do Oriente", parte mais substancial do livro, Silva contextualiza o cenário intelectual dos anos 20 e 30 do século passado, destacando a singularidade do pensamento de Freyre neste cenário, que apontou a mestiçagem como valor central da sociedade brasileira, presente desde o português, por ter estado sempre entre dois mundos: Europa e África. Nesse ponto, chama-se a atenção para o fato de que a valorização do colonizador português é realizada ressaltando-se sua herança moura, ela teria sido imprescindível para a formação de uma civilização nos trópicos, que abarcaria não apenas o Brasil. Como nos indica a autora: "O retrato que Gilberto Freyre Compõe do colonizador é, assim, o de um Portugal extremamente influenciado, 'avivado', 'requeimado', 'tingido', 'amolecido' pela África, pela 'mística sensual do Islamismo"” (p. 31).

Outro importante argumento desenvolvido por Freyre que é apontado no livro é que não apenas haveria uma herança Oriental, mas que haveria de fato uma superioridade cultural dos norte-africanos que invadiram a Península Ibérica, e que as Coloniais portuguesas se beneficiaram muito mais da energia dos moçárabes que dos nórdicos. Desse "biconitentalismo" português proviria o "bambo equilíbrio de antagonismos", que possibilitaria um "contraste de impossíveis", e no caso do Brasil isso implicaria em uma gênese com um pé no Oriente e outro no Ocidente, este equilíbrio teria durado pelos três primeiros séculos da colonização, segundo Silva, o desequilíbrio dos antagonismos seria o eixo principal de análise de Sobrados e Mucambos.

Nesse ponto a autora recorre a Edward Said, a partir de sua obra Orientalismo, para refletir sobre as relações históricas entre Oriente e Ocidente, anunciando que Freyre foi na contramão do que é indicado por Said, na medida em que em pleno momento histórico em que as políticas migratórias buscavam evitar o "perigo amarelo" Freyre defendeu a ideia de que "[...] a cultura brasileira havia sido gerada a partir de uma matriz oriental de valores, hábitos e conceitos sobre o mundo" (p. 39), desse modo, Freyre teria produzido um orientalismo às avessas.

Silva elenca os vários aspectos da cultura brasileira que indicariam a presença Oriental, apontados por Freyre já em Casa-Grande \& Senzala, que 
vão para além da presença substanciada em "chafarizes", "telha mourisca", "gelosia" etc., tendo sido determinantes na conformação da sensibilidade brasileira, desse modo, a ascendência hispâno-árabe teria sido mais forte que a europeia. Os saberes orientais teriam permitido a formulação dessa civilização moderna nos Trópicos. Mesmo o que seria tido como irracional por parte do Oriente, em oposição à racionalidade Ocidental, Freyre valoriza "[...] e a define como saber empírico, vivência, mas também como intuição e conhecimento místico" (p. 43).

Interessante notar que os vários exemplos empíricos da presença Oriental na cultura brasileira que estão presentes em Casa-Grande \& Senzala, e que são destacados por Silva, não configuram uma compilação aleatória de fatos, pois como bem nos indica o próprio Gilberto, ao escrever sobre suas motivações para escrever sua obra mais conhecida:

[...] o que se destaca em Casa-Grande \& Senzala não é a importância dos fatos como fatos; e sim a relação entre eles. A sua projeção em símbolos. Pois é certo, também, do mesmo livro, que o autor não se limita a apresentar fatos de caráter sociológico, isto é, antes recorrências cotidianas do que ocorrências excepcionais. Vai além e procura captar, fixar e destacar nesses fatos o que neles forma, ou são, valores e, além de valores, símbolos, ligados, uns, principalmente ao presente, outros, principalmente a um passado que, de simples realidade histórica, passasse, pela persistência desses símbolos em sucessivas ou, mesmo, descontínuas fases de experiência humana - no caso, a experiência brasileira - as realidades, além de históricas supra-históricas. ${ }^{3}$

E é com esse cuidado que Silva nos apresenta Freyre, exibindo-nos não um emaranhado de fatos narrados por este ilustre sociólogo, mas sim uma série de pistas que nos é dada no conjunto de obra que visavam subverter a forma de pensar o Oriente, e o Brasil, que seria uma espécie de Oriente renascido nos trópicos. Entretanto, visando esclarecer o leitor sobre a compreensão do termo Oriente na obra de Freyre ela nos indica que: "No seu discurso, o Oriente é uma ampla matriz cultural que abriga todos os valores não europeus e, inclusive, antieuropeus. E nesse sentido, o Oriente é evocado como matriz fundante do modo de ser brasileiro. [grifo da autora]" (p. 45).

Seguindo a leitura, a autora adentra em Sobrados e Mucambos, no qual seria apresentado o Brasil do século XIX, tendo como marco a chegada da família real portuguesa, como o capítulo dramático do embate entre Oriente e Ocidente, no qual teria ocorrido um movimento de reeuropeização do Brasil, que implicaria em uma transição a um paradigma ocidental de cultura, entendido como um empobrecimento da cultura brasileira. 
Silva expõe como de forma dramática Freyre percebe o avanço de elementos franco-ingleses em detrimento de um Brasil autêntico, de formação oriental. Toda a herança, sabedoria e tradição oriental seriam postas em xeque com a reeuropeização do Brasil no século XIX, em prol de hábitos e vestimentas inadequados aos trópicos. Essa dualidade entre o Brasil de herança Ibérica, o que nessa leitura implica em uma herança Oriental, e a influência franco-inglesa remete-nos à análise realizada por $\mathrm{Motta}^{4}$ da obra de Freyre, ao indicar que ele seria um verdadeiro "anti-weberiano", ao apontar para outra lógica de tempo, um "tempo ibérico" em oposição a um "tempo nórdico", portanto, a realidade cultural existente no Brasil seria uma antinomia daquela que se difundia no decorrer do século XIX.

É-nos indicado que o período retratado em Sobrados e Mucambos é aquele marcado pela perda da batalha do Oriente com relação ao Ocidente, mediante a difusão de um programa de progresso e civilização claramente ocidental, que teria sido levado a cabo pela República. De tal modo que:

[...] o Brasil se afastava de si mesmo, traía suas origens e se entregava, irrefletidamente, a um processo de descaracterização que, longe de transformá-lo numa Europa tropical, corria o risco de fazer dele um monstruoso arremedo de lorde inglês. O Brasil do século XIX, tal como pintado por Gilberto Freyre, é, assim, uma sociedade cingida pelo conflito, ameaçada na sua identidade, corrompida em seus valores culturais. Na medida em que se afasta do Oriente para embarcar no sonho da "civilização ocidental", o país enterrava suas chances de felicidade futura. Ademais, o drama do Oriente versus Ocidente assumia outras facetas, criando fossos cada vez maiores entre os vários pedaços de Brasil (p. 56).

Esse afastamento do Oriente possuiria, portanto, implicações maiores na obra de Freyre, pois o "equilíbrio de antagonismos" estaria ameaçado, elemento central da cultura brasileira, e é devido a tanto que a distância entre o Sobrado e o Mucambo seria maior que entre a Casa-Grande e a Senzala. É nesse ponto que a autora se questiona: onde estaria esse Brasil mestiço, híbrido e plástico anunciado na obra de Freyre? Para Silva uma das respostas para esse dilema estaria na rua, onde a "comunicação entre as classes" e o "cruzamento entre as raças" seria facilitado, e outra estaria no mulato, que continuaria produzindo intimidade entre as várias partes da sociedade brasileira.

Na última parte do livro intitulada "Improviso" a autora retoma alguns dos argumentos já apresentados, afirmando que para Freyre a impureza e a contaminação ganham um novo status, pois seriam mecanismos de produção de uma cultura infinitamente mais rica e interessante que a branca, o que se 
mostraria ainda mais profícuo no caso brasileiro tendo em vista o alto grau de plasticidade de sua cultura, já presente no português. Ela sintetiza suas principais conclusões da seguinte forma:

Gilberto Freyre [...] criou uma espécie de orientalismo às avessas, na medida em que inverteu os sinais do discurso Orientalista, associando o valor positivo ao Oriente e o valor negativo ao Ocidente. Depois de fazer essa inversão, Gilberto Freyre associa a formação brasileira - em suas raízes, tendências e valores característicos - ao Oriente, termo que na economia simbólica do autor de $S M$ abriga tudo que seja ou signifique "não europeu" ou "antieuropeu". Mostrei, assim, como Gilberto Freyre concebe o Brasil colonial em termos de um paradigma oriental de cultura eu usa, posteriormente, para criticar o que ele chama de reeuropeização da sociedade brasileira, no século XIX (p. $61)$.

As questões trazidas em Orientalismos Brasileiros nos levam a reflexões muito mais profundas que transcendem um simples exame da obra de Freyre no sentido mais estrito, pois como Silva ainda nos aponta dessa discussão podemos tirar ao menos duas lições relevantes para pensar as questões do mundo contemporâneo, do 11 de setembro à Primavera Árabe: a primeira seria o valor da impureza, e a segunda seria a importância da compreensão do valor da empatia como método de indagação do real.

Apesar de seu exame deixar de lado uma análise mais minuciosa de outras obras de Freyre como Uma Cultura Ameaçada: A Luso-Brasileira (1942), Integração Portuguesa nos Trópicos (1958), Novo Mundo nos Trópicos (1959), O Luso e o Trópico (1961), que são fruto de uma reflexão posterior do autor, tocando em alguns dos elementos que Silva levanta, devemos reconhecer que este livro traz um novo olhar sobre o legado intelectual de Freyre, mais que isso, nos lança novas questões para pensarmos a relação entre o Oriente e a cultura brasileira.

A possibilidade de subversão da interpretação da história e da cultura brasileira aberta por esse orientalismo às avessas de Freyre é, no mínimo, original, e pode servir de base para outros programas de investigação tanto da obra freyreana, quanto da sociedade brasileira, de modo que ampliemos nosso olhar sobre a presença Oriental no Brasil. 


\section{NOTAS}

${ }^{1}$ FONSECA, Nery da Fonseca. Nota do Editor. In: FREYRE, Gilberto. China Tropical. Brasília: Editora Unb, 2003. p. 9-10.

${ }^{2}$ Denominação genérica que se refere aos povos que ocuparam a Península Ibérica durante a Idade Média, principalmente os árabes e berberes.

${ }^{3}$ FREYRE, Gilberto. Como e porque sou e não sou sociólogo. Brasília: Editora da Universidade de Brasília, 1968. p. 119.

${ }^{4}$ MOTTA, Roberto. Reação a Max Weber no pensamento brasileiro: O caso de Gilberto Freyre. Estudos de Sociologia, v. 13, p. 185-206, 2008.

Resenha recebida em agosto de 2013. Aceita em agosto de 2013. 